\title{
THE EFFECT OF SELF EXPRESSIVE VALUE AND PERCEIVED VALUE ON MALAYSIAN COSMETIC BRAND LOYALTY: THE MEDIATING ROLE OF BRAND IDENTIFICATION \& WORD OF MOUTH
}

\author{
Norzalita Abd Aziz ${ }^{1 *}$ and Hafaz Ngah ${ }^{2}$ \\ ${ }^{1}$ Graduate School of Business, Universiti Kebangsaan Malaysia, Malaysia \\ E-mail: eita@ukm.edu.my \\ ${ }^{2}$ School of Maritime Business and Management, Universiti Malaysia Terengganu, \\ E-mail: hafazngah@gmail.com
}

\begin{abstract}
Competition in the cosmetic industries is stiff as more industrial players are striving to capture the market in Malaysia. Cosmetics play a crucial role in addressing image or presentation to others. There is a dearth of information concerning consumers' perception of the Malaysian Cosmetic Brand (MCB). This article aims to understand how Self-Expressive Value (SEV) and Perceived Value (PV) relate to Brand Identification (BI) and Word of Mouth (WOM) among consumers. Using a self-administered questionnaire contributed to a total of 261 usable respondents and the PLS results indicate that there is a significant relationship between $\mathrm{PV}$ and SEV on BI and WOM while BI and WOM meditate the relationship between PV and SEV with Customer Loyalty. This article provides some insights on current local consumers perception and behaviour towards Malaysian cosmetic brands. Thus, MCB marketers need to emphasise the value of their products and reflect consumers' self-expressive value that will enhance their brand identification and WOM among consumers which may lead to loyalty among users.
\end{abstract}

Keyword: self-expressive value, perceived value, brand identification, word of mouth, customer loyalty, Malaysia cosmetics brand.

\section{ARTICLE INFO}

Article History:

Received: 17 December 2018

Accepted: 19 March 2019

Published: 30 April 2019 


\section{INTRODUCTION}

Cosmetics used to describe hierarchy in social class and have been used in many parts of the world such as Egypt, China, India, Japan and England many centuries ago. (Keville \& Green, 1995; Chaudri \& Jain, 2009). In Malaysia, the usage of traditional medicine and cosmetics still prevails among the locals such as the Malay practices and beliefs that have been rooted in their culture. Cosmetics played an important role in many cultures and human history, which influences human lives from a religious perspective to the health of general human beings (Johar et al., 2001). Competition in the cosmetics industry is obviously stiff as more and more industrial players are striving to capture more markets in Malaysia. Sales of Malaysian cosmetic brands products are influenced by rising urbanization, increasing rates of women in the workforce, fierce advertisement and promotions among the traders.

Studies also indicate that the desire to look good, enhancing confidence levels and following the trend are some of the reasons why consumers use cosmetics. Malaysian consumers spent about US $\$ 407$ million on cosmetics and personal care in 2013. However, the current slow economic growth and the rising cost of living, have affected the demand for beauty and personal care products among consumers in Malaysia. Many local consumers prefer to switch to cheaper alternatives as reported by Euromonitor in 2016. According to the Federation of Malaysian Manufacturers - the Malaysia Cosmetics and Toiletries Industry Group (FMM- MCTIG), there are more than 50 firms from small to medium-sized companies producing cosmetics. There are several categories of cosmetic products in Malaysia, namely colour cosmetics, skincare, perfumes and fragrances, toiletries and hair care. Among the famous brand names for Malaysian brands are Simply Siti, Sendayu Tinggi, D-Herbs, De' Putih V'Asia, Zam-Zam Oil and many more. As reported by the News Straits Times in January 2018, new customers have emerged in Malaysia who prefer to buy cosmetics and beauty products from independent local producers. Customers are willing to experience more adventurous cosmetic product types due to high competition in the cosmetic business especially when the producers offer niche value products such as those with halal elements that are being sold in the Malaysian cosmetic markets such as Zawara, Nurrayysa Beauty, Sugarbelle and many more. 
Cosmetics not only change one's appearance, but it provides for a sentimental value into one's life as well as the hierarchy of social appearance in many societies that effect consumers' impression of various brands. (Wood, 2004). The study is based on the social identity theory which indicates that consumers will identify, with brands that be able to show attractiveness self -identity and positive feelings (Chernav et al., 2011; Bhattacharya \& Sen, 2003; Fournier, 1998). According to Turner et al. (1994) and Bannnnister and Hogg (2004), the social identity theory is a self-evaluation of individuals to which they belong to and relate to their values. People always associate themselves with brands that carry a positive value as well as meanings. This results in a brand identification concept which is related to the social identity theory that looks at participation within consumers, social approval and group recognition (Mohezar, et al., 2016; Bergami \& Bagozzi, 2000).

This article examines the influence of Self-Expressive Values and Perceived Value on Brand Identification and Word of Mouth and their role in enhancing customer loyalty in Malaysia. Cosmetic products are experiencing an increasing demand which in turn leads to the growth of many Malaysian cosmetic brands that compete along with international brands. The American Marketing Association (AMA) defined a brand as a name, sign, term, design or symbol or a combination of them for the purpose of identifying the products or services of one seller or a group of sellers and subsequently to distinguish them from competitors (Kotler et al., 2009) and Aaker (1997) has built a new benchmark for measuring brand names. The customers of cosmetic brands are not only women but men have shown similar interest in cosmetic brands. They accept cosmetic products for its ability to enhance their physical appearance. The consumption of cosmetic brands is expected to increase from year to year. Since 2008, the local cosmetic industry in Malaysia has been experiencing a rapid growth and Malaysian consumers seem to be ready to pay a higher price for cosmetics that provide quality (Abdullah et al., 2010).

Although previous research has highlighted the importance of brand-related studies such as perceived value, brand identification, but understanding is still lacking about consumers in Malaysia especially in relation to Malaysian Cosmetic Brands: first, the role of Perceived Value and Self Expressive Value on Brand identification and WOM; second, the impact 
of these factors in influencing customer Loyalty in Malaysian Cosmetic brands The Malaysian cosmetic brands (MCB) have been accepted by many Malaysians due to changes in customer preferences that are largely due to advertisements and promotional activities done by cosmetic producers. Moreover, demand for local cosmetic brands is due to an increasing demand for halal cosmetics and more studies are needed because of the changing behaviour of consumers in Malaysia (Hassali et al., 2015; Country Market Insight, 2009). Krishnan et al. (2017) indicate that Malaysia consumers purchase cosmetics to enhance their confidence level, looks and to follow the current trend in the market.

There is still a lack of studies addressing local consumers' values towards MCB There is a vague understanding of factors that significantly influence customer acceptance towards Malaysian cosmetic brands. Thus, this study hopes to provide a clear understanding of crucial factors contributing to customer loyalty towards Malaysian cosmetic brands. Malaysia is experiencing a rapid growth and urbanization in which the use of cosmetics is inevitable. The analysis will identify the demographic profile of the cosmetic customer, particularly in Malaysia. The study seeks to provide usable information about Malaysian customer's perception of values on MCB. The information is crucial for producers, retailers and marketers to understand Malaysian customers purchasing behaviours such as acceptance and perception towards the local cosmetic brands, advertisement and promotional efforts. Therefore, this study explores whether Self Expressive Value and Perceived Value of MCB are associated with Brand Identification and Word of Mouth. Further, this study examines their roles in enhancing loyalty among MCB consumers.

\section{LITERATURE REVIEW AND HYPOTHESES}

\section{Self- Expressive Value}

Self-expressive value can be defined as customers' positive feelings with regard to the brand (Walfred et al., 1995, Wallace et al., 2017). Selfexpressive value is an individualizing character of the one's self for certain value, thoughts and traits. In this context, customers are encouraged to stand on their uniqueness and individuality. (Kim \& Markus, 1999; Markus \& 
Kitayama, 1994). Previous research have shown that the distinctiveness of a brand and self-expressive value influence the attractiveness of brand identification. The customer may consider a cosmetic brand as an individual or in some cases as a companion when there is a match between selfexpressive value and brand identification. It can be said that brand loyalty occurs when the consumer stands on positive feelings when they use the products. Brands have to position well to positively reflect customers' feelings. It is estimated that the more the brand has self-expressive value; the customers are more loyal towards the cosmetic brand (Chung \& Fischer, 2001).

Cosmetic brand choices by customers reflect customer's feelings, philosophy, values affiliated with customer's resources. The selection of specific cosmetic brands can often address specific attributes in terms of external appearance, for example, social roles, belongingness and social status of a particular society (Kim \& Aimee, 2009). To enhance connections between East Asian consumers, they choose items that represent similarity (Kim \& Markus, 1999). Positive feelings by cosmetic brands and products consist of the feeling of wellbeing enhanced by eliminating feelings or at least reducing worry and guilt, which is the main factor with the highest impact explaining why consumers use cosmetics. Brand personality relates to expressive values that are common characteristics of the brand to be perceived favourable and have many advantages to marketers such as to increase loyalty among users (Kim, 2000). According to Wallace et al. (2017) and Godey et al. (2016), there is a positive relationship between self-expressive with word of mouth. They further explained that brand expressive values allow consumers to increase their identity and associate with their self-concept and identity (Wallace et al., 2017, 2014; Hollenback \& Kaikati, 2014; Sprott et al., 2009) and it can enhance brand WOM and loyalty among consumers. Consumers will facilitate by showing their self- expressive value through sharing, updating and discussing the brand that they like to community members and friends (Wallace et al., 2071; Verneccio et al., 2015; Ruane \& Wallace, 2015). Hence, this may indicate that self-expressive value is an important factor of the consumers' response towards brand identification and developing word of mouth traits among them. Thus, it is hypothesised that; 
$\mathbf{H}_{1}$ : Self-expressive value is positively associated with brand identification among consumers.

$\mathbf{H}_{2}$ : Self-expressive value is positively associated with word of mouth among consumers.

\section{Perceived Value}

The common definition of customer perceived value is an assessment of customer product or services by considering their give and receive (Ulaga, 2000). Customer perceived value is also a subjective value by balancing the gain and loss after the process (Yuan \& Wu, 2008). Zeithaml (1988) suggests that perceived value can be regarded as the overall assessment of a consumer regarding the utility of a product (or service), which is thought to be based on perceptions of what is received and what is given. In summary, customer perceived value can be defined as quality of value after comparison of customer's benefits and sacrifices. Woodruff (1997) suggests that creating consumer value will increasingly become a critical source of competitive advantage for companies. Customer value can be viewed in two main dimensions: Extrinsic value and intrinsic value. Extrinsic value, known as utilitarian value, occurs when consumption is appreciated for its function and utility. Intrinsic value is also called hedonic value which occurs when the consumption experience is appreciated as an end in itself, that is, for its own sake (Holbrook, 1986).

Customer emotion is very subjective. Urbanisation s significantly influences customer's preferences and lifestyle, highly sophisticated customers are increasingly demanding functional and convenience cosmetic brands in forms of cosmetic appearance (packaging), application and message delivery on cosmetic products (Abdullah et al., 2010). In order to compete in the market place, it is essential to know the strategic decision to deliver and create value in order to survive (Chihyung et al., 2011). Thus, it is crucial to understand customer perceived value in purchasing behaviour among consumers (Jensen, 1996; Ostrom \& Iacaucci, 1995). Considering limited academic research in this context, there is a need to explore the perceived value of Malaysian cosmetic brands among the locals. Customer perceived value can also be defined as an exchange between multiple advantages and suppliers offering sacrifices as viewed by decision makers in a customer's firm and taking into account the available options of offerings from suppliers in a specific condition (Eggert \& Ulaga, 2002). 
Customer perceived value comprises of 'giver factor' which means the cost of the buyer when getting the offerings and 'take factor' which means the advantages obtained by a purchaser from the supplier or retailer (Dodds, 1991; Zeithmal, 1998). Craik (1993) explains that consumers who purchase cosmetics will always relate to their judgement of values based on certain characteristics over others and that will definitely influence their brand choice. Consumers use cosmetic products to enhance appearance and feelings about themselves and these have an effect on consumers' impression of various cosmetic brands (Wood, 2004). This relates to emotional values that are linked to impulsive and compulsive purchasing behaviour involving pleasurable intrinsic oriented motivation, which, is more subjective in nature. Customers purchase selected brands in order to gain certain emotional and functional value. These can satisfy their needs and enable them to enhance group identification and sense of belonging (Holt, 1995). According to Karim et al. (2013), consumers are more influenced by hedonic or emotional values rather than functional values in terms of products related to appearance and beauty. Kwok et al. (2015) suggested that any product needs to highlight their brand through enhancing all value dimensions which are linked to brand identification and purchase intention. Therefore, it is postulated;

$\mathbf{H}_{3}$ : Perceived value is positively associated with brand identification among consumers.

$\mathbf{H}_{4}$ : Perceived value is positively associated with word of mouth among consumers.

\section{Brand Identification}

Customer normally project themselves by choosing brands that suit them. The level of brand exposures and enhancements in terms of identity is evaluated by the degree of brand identification. According to Aaker (1997), brand identity is a unique set of brand associations that the brand strategist aspires to create or maintain. These associations represent what the brand stands for and imply a promise to customers. Brand identity should help establish a relationship between the brand and the customer by generating a value proposition involving functional, emotional, or self-expressive benefits. Brand identification can be defined as how the brand wants to be viewed and is connected to the marketing approach of the firm (Kang \& 
Sharma, 2012). Brand identification acts as a benchmark of the customerbrand relationship's strength communicated through an additional role behaviour that expresses and enhances the individual identity (Du et al., 2007; Ashforth \& Mael, 1989).

Social brand identification indicates an individual's sense of belonging to a specific group or firm and it is congruent with self-concept (Kressmann et al., 2006; Bhattacharya et al., 1995). Customer identification with a specific brand or a specific firm allows the customer to distinguish the brand from other brands. In social psychology, the concept of social identity is widely used. In the theory of social identification that is widely used which is similar and related to the practise of brand identification such as brand's prestige, level of expectation and duration of membership (Mael \& Ashforth, 1992). Positive word of mouth is said to be derived from the impact of brand loyalty and brand identification (Kim et al., 2001). When a brand assists a customer to enhance him/herself, and when the customer recognizes the brand name, the brand is said to be attractive (Belk, 1988). This study further explored as suggested by Bergkvist \& Bech-Larsen (2010), Camelia (2005), Batra et al., (2011), Kwok et al. (2015) Papista and Dimitriadis (2012) that brand identification serves as an important attribute that will lead to the intention to purchase, consumption or love of the brand and consumers become loyal to the brand. Therefore, it is proposed;

$\mathbf{H}_{5}$ : Brand identification is positively associated with word of mouth among consumers.

$\mathbf{H}_{6}$ : Brand identification is positively associated with loyalty in brand usage.

$\mathbf{H}_{\mathbf{8}}$ : Brand identification mediates the relationship between perceived value and brand loyalty.

$\mathbf{H}_{\mathbf{9}}$ : Brand identification mediates the relationship between self-expressive value and brand loyalty.

\section{Word of Mouth}

The effectiveness of word of mouth and loyalty is said to be higher when there is a high tendency for brand identification. The positive feedback derived from the experience of product usage earns greater success in social communication and has a higher impact on feelings and leisure. As word of 
mouth on the product increases, the tendency for a customer to search for more information on the product is expected to be increased. For instance, they may choose the best option by testing different brands that have been mentioned by consumers' word of mouth (Coulter et al., 2003). Satisfaction using the product communicated by the customer is easily updated as new user experience takes place (Oliver, 1999). Consumers are considered actors in social systems, and consumers' satisfaction can be expressed verbally by exposure to the brand name and can act as an input for verbal judgement, influencing brand identification, perceived value and loyalty (Kozinets et al., 2010; Christopher et al., 2013) Desires to share with others will spread information and comments to reduce dissonance. Moreover, consumers engage in word of mouth to influence others about their choices and express themselves through their brand choice and stimulate behaviour (Kozinets et al., 2010; Iyenger et al., 2009). On the basis of these findings, it is expected that there is a positive effect of word of mouth on brand loyalty among consumers. Thus, it hypothesized:

$\mathbf{H}_{7}$ : WOM is positively associated with brand loyalty among consumers.

$\mathbf{H}_{\mathbf{1 0}}$ : WOM mediates the relationship between perceived value and brand loyalty.

$\mathbf{H}_{11}$ : WOM mediates the relationship between self-expressive value and brand loyalty.

\section{Customer Loyalty}

Oliver (1997) defines loyalty as a deeply held commitment to re-buy or re-consumption of a preferred product consistently in the future. It is believed that loyalty to brand occurs due to a high satisfaction level with the brand and hence consumers decide to continue the relationship with the brand name (Fornell, 1992). As explained by McKercher et al. (2011) loyalty behaviour will cause a repetitive purchase off the same brand or same brand set despite the situational influences and marketing efforts that will not switch behaviour. The relationship that is built over time will lead to more tolerance from a customer that discourages customers from comparing with other brand names. Customers' evaluation of the value of the brand on offer such as price and general assessment of retailers and producers are crucial in enhancing a relationship and loyalty as well as WOM (Carmelia, 2005; Christopher et al., 2013). 


\section{Conceptual Framework}

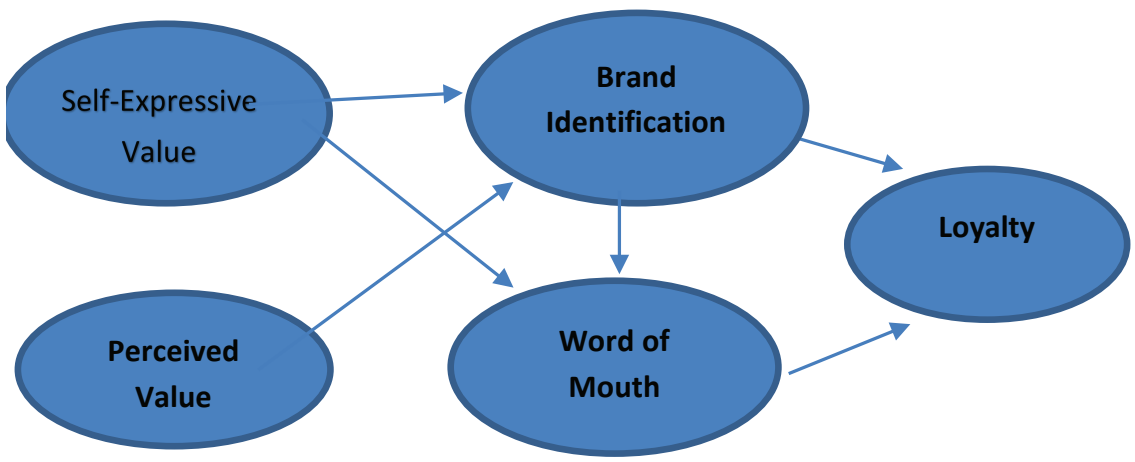

\section{METHODOLOGY}

The survey is the predominant research method used in this study. The data for this study were collected using self-administered questionnaires. These were distributed to individual customers who visited shopping malls in the identified central business districts throughout the primary areas in the Klang Valley. Five identified shopping malls and in each mall, an enumerator was selected to distribute and collect the questionnaire. This sped up data collection and helped ensure the right collection of data needed. Control measures were undertaken to obtain diversity in terms of gender, ethnicity, etc. This approach was chosen because the researcher found that it facilitated speedy distribution as well as enabled more reliable responses (Aziz et al., 2003). Lewis (1984) stated that in a quantitative research, the larger the sample, the smaller the sampling error and the more accurate the survey. Therefore, 400 questionnaires were distributed to five identified malls; Alamanda \& IOI City Mall in Putrajaya, KLCC in Kuala Lumpur, SACC Mall in Shah Alam, Bangi Gateway in Bangi and 261 usable data were secured.

The sampling unit was drawn from a population who use cosmetics in their daily life including men and women. The researcher applied a convenience sampling technique and screening questions were used to identify the respondent's usage of various types of cosmetics. Respondents who answered "yes" were then asked to proceed with the next section of 
the questionnaires. The beginning part which is Part A was concerned with the screening question for the respondents to determine their suitability in answering the questions specifically on the usage of cosmetics. Part B dof 5 different sections. Section A provided information on self -expressive value towards MCB (Malaysian Cosmetic Brand). Section B of the questionnaires elaborated on the perceived value towards the MCB. Section C, D and E explainedon brand identification, word of mouth and loyalty towards the MCB respectively. The final part of the questionnaires (Part $\mathrm{C}$ ) provided demographic profiles of the respondents. For the scaling of measurement, this study was based on Staffords and Wells (1998) and Powpaka (1996) with all the constructs measured using a six-point Likert scale. This was to avoid the clustering of responses at the neutral point, respondents usually use a neutral response as a dumping point when they prefer not to choose or they have no opinion on the statement given. Furthermore, odd numbers of categories include an additional category that is usually identified as the neutral position and it is often argued that the inclusion of a neutral category lures the respondent to remain non-committal (Quee, 2002). Each item had the anchors "Strongly Disagree" and "Strongly Agree", using six-point Likert scales.

\section{FINDINGS}

Socio Demographic Profile

Table 1: Profile of the Respondents

\begin{tabular}{cccc}
\hline & Characteristics & Frequency & Percentage \\
\hline \multirow{2}{*}{ Gender } & Male & 161 & 23.8 \\
& Female & 159 & 76.2 \\
\hline \multirow{3}{*}{ Age } & Twenties & 155 & 59.4 \\
& Thirties & 65 & 24.9 \\
& Forties & 29 & 11.1 \\
& Fifties & 8 & 3.1 \\
& Sixties & 4 & 1.5 \\
\hline
\end{tabular}




\begin{tabular}{|c|c|c|c|}
\hline \multirow{6}{*}{ Education Level } & High- School Certificate & 126 & 48.3 \\
\hline & Diploma & 64 & 24.5 \\
\hline & Bachelor Degree & 39 & 14.9 \\
\hline & Master Degree & 24 & 9.2 \\
\hline & Professional & 6 & 2.3 \\
\hline & PhD (Doctorate) & 2 & 8 \\
\hline \multirow{4}{*}{ Marital Status } & Single (never married) & 157 & 60.2 \\
\hline & $\begin{array}{l}\text { Single (divorce, separated, } \\
\text { or widowed) }\end{array}$ & 13 & 5.0 \\
\hline & Married & 90 & 34.5 \\
\hline & Other & 1 & 4 \\
\hline \multirow{8}{*}{ Monthly Income } & Below 1500 & 99 & 37.9 \\
\hline & RM 1500-RM 3000 & 75 & 28.7 \\
\hline & RM 3001-RM4500 & 41 & 15.7 \\
\hline & RM 4501-RM6000 & 23 & 8.8 \\
\hline & RM 6001-RM7500 & 7 & 2.7 \\
\hline & RM 7501-RM9000 & 2 & 0.8 \\
\hline & RM 9001-RM 10500 & 1 & 0.4 \\
\hline & Above RM 10500 & 13 & 5.0 \\
\hline \multirow{4}{*}{ Ethnicity } & Malay & 198 & 75.9 \\
\hline & Chinese & 51 & 19.5 \\
\hline & Indian & 8 & 3.1 \\
\hline & Others & 4 & 1.5 \\
\hline \multirow{7}{*}{$\begin{array}{l}\text { Monthly Expenses on } \\
\text { Cosmetic Brands }\end{array}$} & Below RM 200 & 171 & 65.5 \\
\hline & RM 200-RM400 & 57 & 21.8 \\
\hline & RM 401-RM600 & 21 & 8.0 \\
\hline & RM 601-RM 800 & 8 & 3.1 \\
\hline & RM 801-RM1000 & 2 & 0.8 \\
\hline & RM 1201-RM 1400 & 1 & 0.4 \\
\hline & Above RM 1400 & 1 & 0.4 \\
\hline
\end{tabular}

\section{PLS Data Analysis}

The data were analyzed using the Smart PLS version 3.2.7 software (Ringle et al., 2015) which is a variance-based structural equation modelling (SEM). Since the purpose of the study was to predict the relationship between variables as stated in the research model instead of reproducing a covariance matrix to achieve model fit (Hair et al., 2014). Thus, Structural Equation Modelling (SEM) with Smart Partial Least Squares (PLS) was used instead of Covariance Based SEM. On top of that, data analyzed with the 
Smart PLS does not have the normality requirement. Though, as proposed by Hair et al. (2017), the study tested the multivariate normality by looking at the skewness and kurtosis using the software available at:

https://webpower.psychstat.org/models/kurtosis/results.php?url=07c ec26b03a378ae4e7f9e486774a65e.

The results showed the research data was multivariate not normal, Mardia's multivariate skewness $(\beta=3.522, \mathrm{p}<0.01)$ and Mardia's multivariate kurtosis $(\beta=48.716, p<0.01)$, supporting the decision to use Smart PLS, which is a non-parametric analysis software. As proposed by Anderson and Gerbing (1988), the two-step analytical procedures were applied in the study. The first step is testing the measurement model, and the second step which is testing the structural model. For testing the structural model which is to test the hypothesis generated in the study, the bootstrapping procedure with 500 resamples which is higher than the original sample of the study, followed the procedure mentioned by Hair et al. (2017) to determine the significance level of loadings and path coefficients.

Table 2: Validation of The Measurement Scales

\begin{tabular}{lcccc}
\hline \multicolumn{1}{c}{ Construct } & Item & Loading & CR & AVE \\
\hline Behavioral & BI1 & 0.913 & 0.947 & 0.781 \\
\hline Intention & BI2 & 0.896 & & \\
& BI3 & 0.854 & & \\
& BI4 & 0.865 & & \\
\hline Loyalty & BI5 & 0.888 & & \\
& L1 & 0.868 & 0.944 & 0.772 \\
& L2 & 0.921 & & \\
& L3 & 0.896 & & \\
Perceived & L4 & 0.854 & & \\
Value & L5 & 0.851 & & \\
& PV1 & 0.790 & 0.915 & 0.684 \\
& PV2 & 0.863 & & \\
& PV3 & 0.833 & & \\
& PV4 & 0.865 & & \\
& PV5 & 0.779 & & \\
\hline
\end{tabular}




\begin{tabular}{lllll}
\hline SEV & SEV1 & 0.882 & 0.953 & 0.802 \\
SEV2 & 0.833 & & \\
SEV3 & 0.926 & & \\
& SEV4 & 0.919 & & \\
\hline SErd Of & WOM1 & 0.899 & 0.966 & 0.850 \\
\hline Mouth & WOM2 & 0.941 & & \\
\hline & WOM3 & 0.945 & & \\
\hline & WOM4 & 0.918 & & \\
\hline
\end{tabular}

Note: $\mathrm{CR}$ = Composite Reliability, AVE = Average Variance Explained

\section{Measurement Model}

Firstly, to confirm the measurement model, two types of validity must be met- convergent validity and the discriminant validity. Convergent validity measures the degree to which multiple items measure the same concepts in agreement (Hair et al., 2017). In order to assess the convergent validity of the measurement model, the loadings, AVE and CR must meet the threshold value. The loading must exceed 0.5 and CR must be higher than 0.7. On the other hand, Barclay et al (1995) set up 0.5 as a minimum value for AVE. Table 1 shows that the landings were in the range of 0.779 $-0.945, \mathrm{CR}$ within $0.915-0.966$ and the AVEs were between $0.684-0.850$ and was higher than the threshold value mentioned by Hair et al. (2014) and Barclays et al (1995). Therefore, convergent validity requirements were fulfilled. Secondly, we assessed the discriminant validity. Discriminant validity measures the extent to which a construct is truly distinct from other constructs by empirical standards (Hair et al., 2017), Previously, discriminant validity was measured according to the Fornell and Larcker (1981) criterion. But, due to some criticism in this method, Henseler et al. (2015) proposed a heterotrait-monotrait (HTMT) of the correlation. Henseler et al. (2015) proposed that, if the HTMT is higher than 0.9, it is an indicator that the model lacks discriminant validity. Table 3 below shows that all the values fulfilled the criterion of HTMT0.9 (Gold et al., 2001). Hence, discriminant validity was not an issue in this study. 
Table 3: Convergent Validity

\begin{tabular}{lccccc}
\hline & 1 & 2 & 3 & 4 & 5 \\
\hline BI & & & & & \\
\hline Loyalty & 0.860 & & & & \\
\hline PV & 0.893 & 0.840 & & & \\
\hline SEV & 0.870 & 0.762 & 0.778 & & \\
\hline WOM & 0.819 & 0.832 & 0.776 & 0.748 & \\
\hline
\end{tabular}

Note: $\mathrm{CR}=$ Composite Realibility, AVE = Average Variance Explain

Note: Discriminant validity established at HTMT ${ }_{0.90}$

\section{Structural Model}

Before testing the structural model, it is crucial to confirm that there is no collinearity issue in the structural model. Diamantapoulus and Sigauw, (2006) claimed that the VIF must be lower than 3.3. As shown in Table 4 below, the VIF value for each construct is lower than the conservative value of 3.3. Hence, it indicates that collinearity is not an issue for the study.

Table 4: Collinearity Test

\begin{tabular}{lccc} 
& BI & Loyalty & WOM \\
\hline $\mathrm{BI}$ & & 2.477 & 4.465 \\
\hline $\mathrm{PV}$ & 2.055 & & 3.083 \\
\hline $\mathrm{SEV}$ & 2.055 & 3.045 \\
\hline WOM & & \\
\hline
\end{tabular}

\section{Structural Model Assessment}

Once we confirmed the measurement model and the collinearity issue, we could proceed to the next step which is the assessment of the structural model. Table 5 shows the results of the path coefficient assessment using the bootstrapping procedure to test the hypotheses generated from the research model. From 7 hypothesis tested, all hypothesis was supported. Among the seven hypotheses supported, six of them were significant at the 99 percent confidence interval (SEV $->\mathrm{BI}, \beta=0.471, \mathrm{t}=7.963, \mathrm{LL}=0.346, \mathrm{UL}=0.577$; $\mathrm{PV}->\mathrm{BI}, \beta=0.480, \mathrm{t}=8.500, \mathrm{LL}=0.361, \mathrm{UL}=0.586$; $\mathrm{PV}->\mathrm{WOM}, \beta=0.232$, $\mathrm{t}=2.572, \mathrm{LL}=0.010, \mathrm{UL}=0.041 ; \mathrm{BI}->\mathrm{WOM}, \beta=0.416, \mathrm{t}=4.520, \mathrm{LL}=0.243$, $\mathrm{UL}=0.599, \mathrm{BI}->$ Loyalty, $\beta=0.483, \mathrm{t}=7.610, \mathrm{LL}=0.343, \mathrm{UL}=0.594$ and WOM $->$ Loyalty, $\beta=0.410, \mathrm{t}=6.248, \mathrm{LL}=0.284, \mathrm{UL}=0.536$ and one 
relationship significant at 95 percent (SEV -> WOM, $\beta=0.204, \mathrm{t}=1.961$, $\mathrm{LL}=0.003$, $\mathrm{UL}=0.196$ ). Hence it is confirmed that Self-Expressive value and Perceived Value have a positive relationship with Behavioral Intention and Word of Mouth, Behavioral Intention has a positive relationship with Word of Mouth and Loyalty, and Word of Mouth has a positive relationship with Loyalty.

Table 5: Results Summary of Hypotheses Testing

\begin{tabular}{clccccccc}
\hline Hypothesis & Relationship & $\begin{array}{c}\text { Path } \\
\text { Coefficient }\end{array}$ & $\begin{array}{c}\text { Std } \\
\text { error }\end{array}$ & T Value & P Values & LL & UL & Decision \\
\hline H1 & SEV -> BI & 0.471 & 0.059 & 7.963 & 0.000 & 0.346 & 0.577 & Supported \\
\hline H2 & SEV -> WOM & 0.204 & 0.104 & 1.961 & 0.050 & 0.003 & 0.396 & Supported \\
\hline H3 & PV -> BI & 0.480 & 0.056 & 8.500 & 0.000 & 0.361 & 0.586 & Supported \\
\hline H4 & PV -> WOM & 0.232 & 0.090 & 2.572 & 0.010 & 0.041 & 0.391 & Supported \\
\hline H5 & BI -> WOM & 0.416 & 0.092 & 4.520 & 0.000 & 0.243 & 0.599 & Supported \\
\hline H6 & BI -> Loyalty & 0.483 & 0.063 & 7.610 & 0.000 & 0.343 & 0.594 & Supported \\
\hline H7 & WOM -> Loyalty & 0.410 & 0.066 & 6.248 & 0.000 & 0.284 & 0.536 & Supported \\
\hline
\end{tabular}

Notes: LL, lower limit; UL, upper limit at 95 and 99 percent confident interval.

Table 5 presents the assessment of coefficient of determination (R2), the effect size (f2) as well as the predictive relevance (Q2) of exogenous variables on the endogenous variable in this study. The value for the coefficient of determination (R2) for WOM, BI and Loyalty were 0.633, 0.776 and 0.707 respectively. This suggests that the exogenous variables in this study, namely Self-Expressive Value and Perceived Value explain 77.6\% of the variance in Behavioral Intention, Self-Expressive Value, Perceived Value and Behavioral Intention explain $63.3 \%$ of the variance for Word of Mouth and Loyalty could be explained for $70.7 \%$ by the Behavioral Intention and Word of Mouth. Overall, the Q2 value of $0.503,0.563$ and 0.508 for Word of Mouth, Behavioral Intention and Loyalty respectively which are larger than 0 (Hair et al., 2014) suggesting that all exogenous variables possess predictive ability over the endogenous variable. For the effect sizes, all the endogenous variables to the Word of Mouth, had a small effect size, variables linked to Loyalty had a medium effect size and predictor to the Behavioral intention had a high effect size. All the details are shown in Table 6. 
Table 6: Assessment of Coefficient

\begin{tabular}{|c|c|c|c|c|c|c|c|c|}
\hline Construct & R2 & Q2 & & & Effec & t size & & \\
\hline & & & BI & & Loyalty & & WOM & \\
\hline WOM & 0.633 & 0.503 & & & 0.232 & Medium & & \\
\hline $\mathrm{BI}$ & 0.776 & 0.563 & & & 0.321 & Medium & 0.105 & Small \\
\hline PV & & & 0.500 & High & & & 0.048 & Small \\
\hline SEV & & & 0.482 & High & & & 0.037 & Small \\
\hline Loyalty & 0.707 & 0.508 & & & & & & \\
\hline
\end{tabular}

Table 7: Results Summary of Hypotheses Testing-Mediating Variables

\begin{tabular}{|c|c|c|c|c|c|c|c|c|}
\hline Hypothesis & Relationship & $\begin{array}{c}\text { Path } \\
\text { Coefficient }\end{array}$ & $\begin{array}{l}\text { Std } \\
\text { error }\end{array}$ & $\begin{array}{c}\mathrm{T} \\
\text { Value }\end{array}$ & $\begin{array}{c}\text { P } \\
\text { Values }\end{array}$ & LL & UL & Decision \\
\hline $\mathrm{H} 8$ & $\begin{array}{l}\text { PV }->\mathrm{BI}-> \\
\text { Loyalty }\end{array}$ & 0.232 & 0.042 & 5.576 & 0.000 & 0.161 & 0.320 & Supported \\
\hline $\mathrm{H} 9$ & $\begin{array}{l}\text { SEV -> BI -> } \\
\text { Loyalty }\end{array}$ & 0.227 & 0.042 & 5.447 & 0.000 & 0.149 & 0.311 & Supported \\
\hline $\mathrm{H} 10$ & $\begin{array}{l}\text { PV -> WOM -> } \\
\text { Loyalty }\end{array}$ & 0.095 & 0.044 & 2.150 & 0.032 & 0.017 & 0.190 & Supported \\
\hline $\mathrm{H} 11$ & $\begin{array}{l}\text { SEV -> WOM -> } \\
\text { Loyalty }\end{array}$ & 0.084 & 0.042 & 1.991 & 0.047 & 0.003 & 0.165 & Supported \\
\hline
\end{tabular}

Table 7 shows the results of the mediating variables of $\mathrm{H} 8$ to $\mathrm{H} 11$, as suggested in the literature, while testing the mediation effect, the Preacher and Hayes (2008) method of bootstrapping the indirect effect is applied. Smart PLS version 3.2.7 has a report on the specific indirect effect to demonstrate the result for each indirect effect to test the mediation effect in the research model, which is not available in the previous version. The bootstrapping analysis results for $\mathrm{H} 8$, (PV $->\mathrm{BI}->$ Loyalty) $\boldsymbol{\beta}=0.232$, $t=5.576, \mathrm{LL}=0.161, \mathrm{UL}=0.320, \mathrm{H} 9,(\mathrm{SEV} \rightarrow \mathrm{BI}->$ Loyalty), $\boldsymbol{\beta}=0.227$, $t=5.447, \mathrm{LL}=0.149, \mathrm{UL}=0.311, \mathrm{H} 10$ (PV $->$ WOM $->$ Loyalty), $\boldsymbol{\beta}=0.095$, $t=2.150, \mathrm{LL}=0.032$, $\mathrm{UL}=0.017$, and $\mathrm{H} 11$, (SEV $\rightarrow>$ WOM $\rightarrow$ Loyalty), $\boldsymbol{\beta}=0.084, t=1.991, \mathrm{LL}=0.047, \mathrm{UL}=0.003$, shows that all the relationship were supported. As indicated by Preacher and Hayes (2008), LL and the UL does not straddle a 0 in between indicating there is a mediation effect between the independent variable and the dependent variable. Hence, we can conclude that Behavioral intention (BI) and Word of Mouth WOM) significantly mediated the positive relationship between Self expressive value (SEV) and Loyalty and also the relationship between Perceived Value $(\mathrm{PV})$ and Loyalty. 


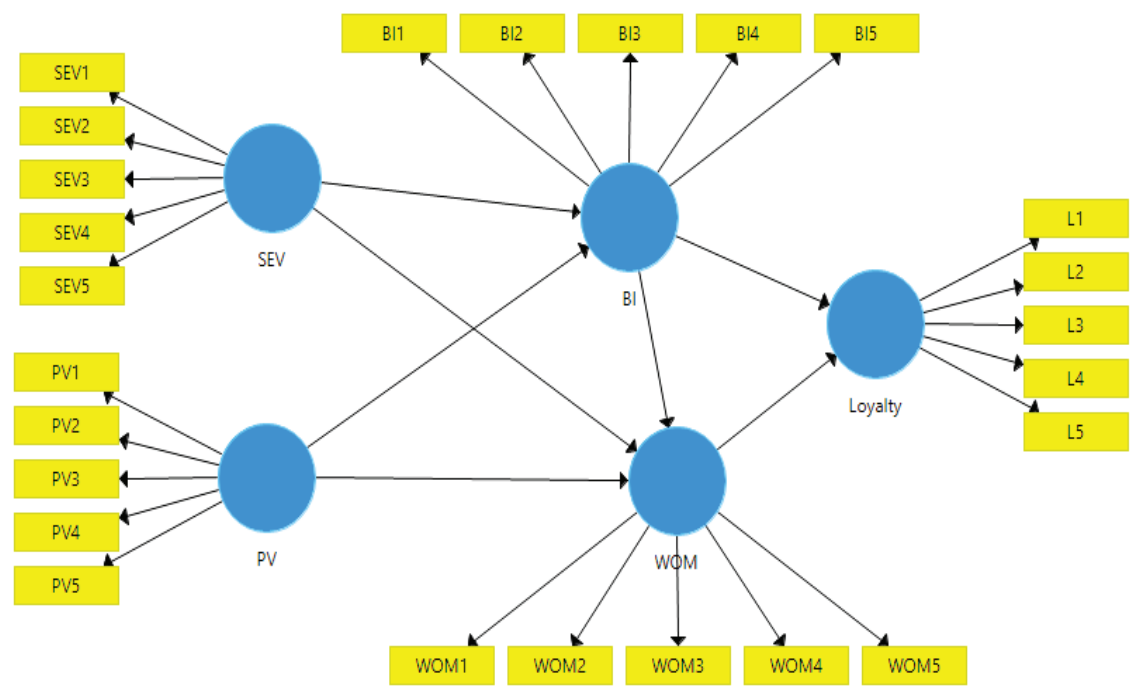

Figure 2: Structural Model

SEV - Self-Expressive Value, PV-Perceived Value, BI - Brand Identification, WOM- Word of Mouth, Loyalty

\section{DISCUSSION AND CONCLUSION}

The findings show that Brand Identification (BI) (SEV) and WOM were significantly influenced by Perceived Value (PV) and Self Expressive Value (SEV). The results, show that perceived value and self-expressive value are two important factors in the formation of brand identification among Malaysian local cosmetic users. There are no significant differences between the two variables, whereby the value of PV is just slightly higher than SEV. Moreover, there is no significant difference between PV and SEV in influencing WOM among domestic users. The findings show that perceived value is slightly important in influencing WOM compared to selfexpressive value even though both PV and SEV are significant variables in influencing BI and WOM. The study explains that SEV and PV of Malaysian cosmetic brands represent positive, attractive and meaningful meanings to consumers. Consumers can identify themselves as well as a sense of belonging to a specific brand. Moreover, PV and SEV allow consumers to consume cosmetic brands that they are familiar with. As explained in the social identity theory, PV and SEV can incorporate the brand into consumers' self-concept or identity that represents the brand identification in terms of 
cognitive and emotional aspects as mentioned in studies done by Turner et al. (1994) and Bannister and Hogg (2004). Chernav et al. (2011) explain that consuming a certain brand, shows that the user belongs to a selected group of consumers.

The study also showed that positive word of mouth (WOM) is one of the most important factors that creates a positive relationship between the organisation's brand and customers. Psychological constructs such as identity and attitude are some of the crucial antecedents of behavioural constructs such as loyalty and WOM. These support previous studies such as Wallace et al. (2017), Godey et al. (2016), Papista and Dimitriadis (2012), Christopher et al. (2013). Therefore, in order to increase brand identification (BI) by the customer, the Malaysian cosmetic brands (MCB) producers must create a careful plan to determine the aspects that contribute the highest impact on BI and WOM. The PV of customers is the most important antecedent of BI followed by SEV. The outcome achieved from higher PV may result in a higher level of brand identification which subsequently results in repeat purchase behaviour by customers by enhancing WOM and switching brands can be avoided.

Managers of MCB companies need to be alert to the changes in the surroundings in the consumer cosmetic markets. They should be aware that consumers are motivated if they are allowed to express their identity with values that satisfy their needs. The brand name can enhance brand identification by engaging with the media or current social media. The study concurs that social media campaigns with the message of MCB can impress and share with others which will definitely increase the positive $\mathrm{BI}$ as well as WOM and consumption of MCB. The managers of MCB can enhance their brand name and loyalty by associating the endorsers that have the same values that will push consumption loyalty among users. Unfortunately, from observations in the Malaysia market, many MCB organisations fail due to the greater emphasis on short-term objectives only by giving feedback to ad-hoc or adopting strategies of other organisations. Hence, brand identification that is used effectively can assist customers to improve their self- expressive value and vice versa.

Brand identification has a higher tendency to increase the word of mouth and brand loyalty. Brand identification can be communicated by 
performing sales promotions, social and charity activities. It is interesting to note that brand identification is not a simple process, but once it is created, it is expected to have a longer life. The MCB producers, marketers and retailers are also advised to study the Malaysian purchasing behaviour in cosmetic markets. By having a thorough understanding, will enable them to shape customer segmentation for the brands and the marketing approach. Customer loyalty can be increased and customer base can be extended by having better knowledge on how the self-expressive value, perceived value, brand identification and word of mouth actually influence cosmetic usage. As we are aware that social influence is important, MCB managers and producers need to enhance positive WOM and Brand Identification by offering more persuasive information related to the cosmetic. This can be done through endorsers who can give support and a statement of approval as well. This is important to create a greater likelihood of acceptance among consumers.

In addition, the study suggests that $\mathrm{MCB}$ producers, retailers and marketers build effective interaction method to address the attractiveness and distinctiveness of the MCB. Communication is crucial in developing and sustaining brand identification. In addition, MCB managers have to associate the value dimensions that involves emotional as well as functional values in their brands which is in line with the study done by Kwok et al. (2015). Moreover, it is essential to persistently create the identity of the brand, which, requires not only interaction strategies but must be supported by other approaches such as the organisation's community service. To create loyalty on the cosmetic products towards the customer, advertisements and promotions play an important role. The advertisement and promotions must be designed uniquely so as to reflect brand identification. The MCB producers are encouraged to project their cosmetic brands by distributing samples to households. Also, during the promotional period, the MCB producers, marketers and retailers may consider offering free gifts to the customer which in turn will increase the effect of the perceived value and loyalty of customer towards the brands and organisations. Promoting through social media sites, MCB marketers can create activities that will reflect consumers' self-expressive and brand value by encouraging them to share and express themselves with stories that lead to engagement to the brand (Algharabat, 2017). 
Although the study has provided some new insights the limitations of the findings should also be considered. The research is concerned whit respondents who have experienced Malaysian cosmetic brands. Hence, this research does not cover customers who do not have experience in using Malaysia cosmetic brands. Moreover, we note that in our study, more than $50 \%$ of the respondents had an overall average income of less than RM3000 which may influence brand performance and perception of MCB in developing brand identification and WOM. Thus, we are suggesting that it would be interesting to conduct the study in different settings or countries or with different income levels. We advocate that further studies should be conducted using their framework to explore whether there are significantdifferences across $\mathrm{MCB}$ versus global/renowned cosmetic brands in the market. The results disclosed that self- expressive value, perceived value, brand identifications and word of mouth play a crucial role in determining customer loyalty to Malaysian cosmetic brands. To conclude, MCB managers need to understand that to sustain in the market, they should focus on a meaningful brand. Thus the brand needs to have emotional and functional value interaction that can enhance self-identity. The quality features need to be highlighted too in developing the emotional attachment that can lead to positive WOM and loyalty consumption among Malaysian consumers.

\section{REFERENCES}

Aaker, J. L. (1997). Exploring brand equity: Building strong brands. New York: The Free Press.

Abdullah, S., Cheng, W., Mohamad, G., Asma, A. (2010). The mainstream cosmetics industry in Malaysia and the emergence, growth and prospects of halal cosmetics. In the $3^{\text {rd }}$ International Conference on International Studies (ICIS 2010) 1st-2nd December 2010, Hotel Istana Kuala Lumpur. Retrieved on 22 December, 2013 from; http://repo.uum.edu. my/2466/1/Abdullah_Swidi_The_Maintsream_Cosmetics_Industry_ pdf.

Algharabat, R. S. (2017). Linking social media marketing activities with brand love: The mediating role of self-expressive brands. Kybernetes, 46(10), 1801-1819. 
Anderson, J. C., \& Gerbing, D. W. (1988). Structural equation modeling in practice: A review and recommended two-step approach. Psychological Bulletin, 103 (May), 411-423.

Ashforth, B. E. \& Mael, F. (1989). Social identity theory and the organisation. Academy of Management Review, 14(1), 20-39.

Aziz, N. A, Ahmad, A. A., Omar, N. \& Evin, C. (2012). Examining the impact of visitor's emotions and perceived quality towards satisfaction and revisit intention to theme parks. Jurnal Pengurusan, 35, 97-109.

Babin, B. J., Darden, W. R., \& Griffin, M. (1994). Work and/or fun: Measuring hedonic and utilitarian shopping value. Journal of Consumer Research, 20(4), 644-656.

Badaruddin, N. (2018, January 17). The rise of local cosmetic brand. New Straits Times. Retrieved from https://www.nst.com.my/lifestyle/f lair/2018/01/325908/rise-local-cosmetic-brands

Bannister, E. \& Hogg, M. (2004) Negative symbolic consumption and consumer drive for self-esteem: The case of the fashion industry. European Journal of Marketing, 38(7), 850-868.

Barclay, D. W., Thompson, R. \& Higgins, C. (1995). The partial least squares (PLS) approach to causal modelling: Personal computer adoption and use an illustration. Technology Studies, 2(2), 285-309.

Baron, R. M \& Kenny, D. A. (1986). The moderator-mediator variable distinction in social psychological research: Conceptual, strategic, and statistical considerations. Journal of Personality and Social Psychology, 51(6), 173-1182.

Batra, R., Ahuvia, A. \& Bagozzi, R. (2011). Brand love. Journal of Marketing, 76, 1-16.

Belk, R. W. (1988). Possessions and the extended self. Journal of Consumer Research, 15(2), 139-168. 
Bergami, M. \& Bagozzi, R. P. (2000). Self-categorization, affective commitment and group self-esteem as distinct aspects of social identity in the organisation. British Journal of Social Psychology, 39, 55-77.

Bergkvist, L. \& Bech-Larsen, T. (2010). Two studies of consequences and actionable antecedents of brand love. Brand Management, 17(7), 504-518.

Bhattacharya, C. \& Sen, S. (2003). Consumer-company identification: A framework for understanding consumers' relationship with companies. Journal of Marketing, 67(2), 76-88.

Carmeli, A. (2005). Perceived external prestige, affective commitment and citizenship behaviours. Organizational Studies, 26(3), 443-464.

Chaudri, S. K. \& Jain, N. K. (2009). History of cosmetics. Asian Journal of Pharmaceutics, 3(3), 164-168.

Chernav, A., Hamilton, R. \& Gal, D. (2011). Competing for consumer identity: Limits to self-expression and the perils of lifestyle branding. Journal of Marketing, 75(3), 66-82.

Chihyung O. K., Young, G. C. \& Seunghyup, S. H. (2011, July). Roles of brand value perception in the development of brand credibility and brand prestige. Paper presented at the International CHRIE ConferenceRefereed Track. Paper 13. Retrieved from http://scholarworks.umass. edu/refereed/ICHRIE_2011/Wednesday/13

Christopher, M., Paynes, A. \& Ballantyne, D. (2013). Relationship marketing. Routledge, Oxford.

Chung, E. \& Fischer, E. (2001) When conspicious consumption becomes inconspcious: The case of the migrant Hong Kong consumers. Journal of Marketing, 18(8), 474-487.

Coulter, R., Price, L. L. \& Feick, L. (2003). Rethinking the origins of involvement and brand commitment: Insights from post-socialist central Europe. Journal of Consumer Research, 29, 151-169. 
Country Market Insight. (2009). Cosmetics and toiletries in Malaysia. Retrieved on 13 September 2009.

Craik, J. (1993). The face of fashion: Cultural studies in fashion. London: Routledge.

Diamantopoulos, A. \& Siguaw, J. A. (2006). Formative versus reflective indicators in organizational measure development. A comparison and empirical illustration. British Journal of Management, 17(4), 263-282.

Dodds, W. B. (1991). In search of value - How price and store name information influence buyers' product perceptions. Journal of Services Marketing, 5, 27-36.

Du, S., Bhattacharya, C. B. \& Sen, S. (2007). Reaping relational rewards from corporate social responsibility: The role of competitive positioning. International Journal of Research in Marketing, 24, 224-41.

Eggert, A. \& Ulaga, W. (2002). Customer perceived value-A substitute for satisfaction in business markets. Journal of Business and Industrial Marketing, 17(2/3), 107-118.

Fornell, C. G., \& Larcker, D. F. (1981). Evaluating structural equation models with unobservable variables and measurement error. Journal of Marketing Research, 18(1), 39-50.

Fournier, S. (1998). Consumer and their brands: Developing relationship theory in consumer research. Journal of Consumer Research, 24(4), 343-373.

Godey, B., Manthiou, A., Pederzoli, D., Rokka, J., Aiello, G., Donvito, R. \& Singh, R. (2016). Social media marketing efforts of luxury brands: Influence on brand equity and consumer behaviour. Journal of Business Research, 69(12), 5833-5841.

Hair, J. F., Hult, T.M., Ringle, C.M. \& Sarstedt, M. (2014). A Primer on Partial Least SquareStructural Equation Modeling (PLS-SEM). Thousand Oakes, CA: Sage. 
Hair, J. F., Thomas, G., Hult, M., Ringle, C. M., \& Sarstedt, M. (2017). A Primer on Partial Least Squares Structural Equation Modeling (2nd ed.). Thousand Oakes, CA: Sage.

Hassali, M. A., Al-Tamimi, S. K., Dawood, O. T., Verma, A. K. \& Saleem, F. (2015). Malaysia cosmetic market: Current \& future prospects. Pharmaceutical Regulatory Affairs, 4(4), 1-3.

Henseler, J., Ringle, C. M. \& Sarstedt, M. (2015). A new criterion for assessing discriminant validity. Journal of the Academy of Marketing Science, 43(1), 115-135.

Holbrook, M. B. (1986). The role of emotion in the consumption experience: Actions and reactions in consumer behaviour. Advances in Consumer Research, 13, 666.

Hollenbeck, C. R. \& Kaikati, A. M. (2012). Consumers' use of brands to reflect their actual and ideal selves on Facebook. International Journal of Research in Marketing, 29(4), 395-405.

Holt, D. B. (1995). How consumers consume: A typology of consumption practices. Journal of Consumer Research, 22(1), 1-16.

Iyenger, R., Han, S. \& Gupta, S. (2009). Do friends influence purchases in a social network? (Working Paper No. 09-123). Retrieved from http:// ssrn.com/abstract $=1392172$.

Jensen, H. R. (1996). The interrelationship between the customer and consumer value. Asia Pacific Advances in Consumer Research, 2, 60-63.

Johar, N., Mohd Riji, H. \& Pataki-Schweize, K. J. (2001). Perception and use of traditional medical treatment and cosmetics amongst Malay high school adolescents in Kuala Lumpur. Malaysian Journal of Public Health Medicine, 1, 22-29.

Kang, A. \& Sharma, H. (2012). Using Brand Personality to enhance brand trust and perceived value: An empirical study of the brand Lux. AsiaPacific Journal of Management Research and Innovation, 8(3), 323-335. 
Karim, J. A., Kumar, M. \& Abd Rahman, S. (2013). Measuring shopping values of Malaysian retail consumers. Asia Pacific Journal of Marketing Logistics, 25(2), 200-224.

Kim, C. K., Han, D. \& Park, S. B. (2001). The effect of brand personality $\&$ brand identification on brand loyalty: Applying the theory of social identification. Japanese Psychological Research, 43(4), 195-206.

Kim, H. S. \& Aimee, D. (2009). Express your social self: Cultural differences in choice of brand-name versus generic products. Personality and Social Psychology Bulletin, 35(12), 1555-1566.

Kim, H. S. (2000). Examination of brand personality \& brand attitude within the apparel product category. Journal of Fashion Marketing \& Management, 4(3), 243-252.

Kim, H. S., \& Markus, H. R. (1999). Deviance or uniqueness, harmony or conformity? A cultural analysis. Journal of Personality and Social Psychology, 77, 785-800.

Kotler, P., Keller, K., Koshy, A. \& Jha, M. (2009). Marketing management—A South Asian perspective (13th ed.). New Delhi: Pearson Education.

Kozinets, R. V. de Valek, K., Woknicki, A. C. \& Wilnew, S. J. S. (2010). Networked narratives: Understanding word of mouth marketing in online communities. Journal of Marketing, 74(2), 71-89.

Kressman, F., Sirgy, M. J., Herrman, A. Huber, S. \& Lee, D. J. (2006). Direct $\&$ indirect effects of self-image congruence on brand loyalty. Journal of Business Research, 59, 955-964.

Krishnan, S. Amira, N. S., Umi, N. A., Syafawani, S. \& Hafiz, M. (2017). The usage of cosmetics in Malaysia: Understanding the major factors that affect the users. Management, 7(1), 48-51.

Kwok, D. H., Kwon, Y. \& Lim, C. (2015). Licensing a sports brand: Effects of team brand cue, identification and performance priming on multidimensional values and purchase intentions. Journal of Product \& Brand Management, 24(3), 198-210. 
Mael, F. B., \& Ashforth, E. (1992). Alumni and their alma mater: A partial test of the reformulated model of organizational identification. Journal of Organizational Behavior, 13, 103-123.

Markus, H. R., \& Kitayama, S. (1991). Culture and the self: Implications for cognition, emotion and motivation. Psychological Review, 98, 224-253.

McKercher, B. Denizci-Guillet, B. \& Ng. E. (2011). Rethinking loyalty. Annals of Tourism Research, 39(2), 708-734.

Mohezar, S., Zailani, S. \& Zainuddin, Z. (2016). Halal cosmetics among young consumers in Malaysia: Religiousity concern. Global Journal Al-Thaqafah, 6(1), 47-58.

Nadiri, H. \& Gunay, G. N. (2013). An empirical study to diagnose the outcomes of customers' experiences in trendy coffee shops. Journal of Business Economics \& Management, 14(1), 22-53.

Ostrom, A., \& Iacobucci, D. (1995). Consumer trade-offs and the evaluation of services. Journal of Marketing, 59, 17-28.

Papista, E. \& Dimitriadia, S. (2012). Exploring consumer-brand relationship quality \& identification: Qualitative evidence from cosmetic brands. Qualitative Market Research: An International Journal, 15(1), 33-56.

Preacher, K. J., \& Hayes, A.F. (2008). Asymptotic and resampling strategies for assessing and comparing indirect effects in multiple mediator models. Behavior Research Methods, 40(3), 879-891.

Richard, J. E. \& Guppy, S. (2014). Facebook: Investigating the influence on consumer purchase intention. Asian Journal of Business Research, $4(2), 1-15$.

Ringle, C. M., Wende, S., \& Becker, J. M. (2015). SmartPLS 3. Bönningstedt: SmartPLS GmbH. Retrieved from www.smartpls.com.

Ruane, L. \& Wallace, E. (2015). Brand tribalism and self-expressive brands: Social influences and brand outcome. Journal of Product \& Brand Management, 24(4), 333-348. 
Sprott, D, Czellar, S. \& Spongenberg, E. (2009). The importance of a general measure of brand engagement on market behaviour: Development and validation of a scale. Journal of Marketing Research, 46(1), 92-104.

Turner, J., Oakes, P. \& McGarty, C. (1994). Self and collective: Cognition and social context. Personality \& Social Psychology Bulletin, 20, 454-463.

Ulaga, W. (2001). Measuring customer perceived value in business markets: A pre-requisite for marketing strategy development \& implementation. Industrial Marketing Management, 30(6), 525-540.

Vernuccio, M., Pagani, M., Barbarossa, C. \& Pastore, A. (2015). Antecedents of brand love in online network based communities: A social identity perspective. Journal of Product \& Brand Management, 24(7), 706-719.

Wallace, E., Buil, I. \& de Chernatony, L. (2014). Consumer engagement with self-expressive brands: Brand love and WOM outcomes. Journal of Product \& Brand Management, 23(1), 33-42.

Wallace, E., Buil, I. \& de Chernatony, L. (2017). Consumers' self-congruence with a "liked" brand: Cognitive network influence and brand outcomes. European Journal of Marketing, 51(2), 367-390.

Wong, F. Y., \& Yahyah, S. (2008). Influence of brand loyalty on consumer sportswear. International Journal of Economics and Management, 2, 221-236.

Wood, L. M. (2004) Dimensions of brand purchasing behaviour: Consumers in the 18-24 age groups. Journal of Consumer Behaviour, 4(1), 9-24.

Woodruff, R. B. (1997) Customer value: The next source of competitive advantage. Academy of Marketing Science Journal, 25(2), 139-153.

Zeithaml, V. A. (1988). Consumer perceptions of price, quality, and value: A means-end model and synthesis of evidence. Journal of Marketing, $52(3), 2-22$. 